\title{
FROM IDENTITY TO QUEER POLITICS: SHFTS IN THE SOCIAL LOGIC OF NORMATIVE HETEROSEXUALITY IN CONTEMPORARY AMERICA
}

\author{
Steven Seidman \\ State University of New York, Albany \\ Social Thought \& Research, 2002, Vol. 24, 1\&2
}

Since at least the 1950s, a social division between a dominant heterosexual majority and a subordinate homosexual minority has been central to American society. This hierarchy has been maintained, until recently, by primarily repressive practices. These practices create the idea of the heterosexual and the homosexual as antithetical human types and enforce the normative status of heterosexuality by polluting the homosexual. I will argue that in the last decade or so, the norm of heterosexuality has been sustained less by social repression than by normalizing controls. Moreover, I suggest that if we understand gay identity politics as a response to a repressive social logic of normative heterosexuality, a historically unique type of sexual politics, so called queer politics, can be viewed as a response to gay normalization. The normative grounds and political aims of queer politics however have been unclear. In the conclusion, I will propose an ethical-political elaboration of a queer, anti-normalizing politics.

Contemporary American gay culture can be dated from the 1950s. Two events occurred. First, the dominance of a view of homosexuality as a deviant minority identity. Second, there occurred, perhaps for the first time historically, a national campaign to enforce normative heterosexuality by enlisting the state and other social institutions to 
control the homosexual. This societal mobilization, deploying strategies of repression and pollution, gave birth to the era of the closet and identity politics.

Central to this logic is the exclusion of the homosexual from public life. Constructing the homosexual as defiled justifies her exclusion from and public life. Symbolically degrading the homosexual contributes to creating dominated gay selves-that is, individuals for whom shame and guilt are at the core of their sense of self; public invisibility becomes in part self enforced. The exclusion of the homosexual from public life is reinforced by civic disenfranchisement-the denial of civil rights and political representation. Socially segregating the homosexual from the heterosexual is so basic to the repressive logic that everyday antigay violence is tolerated in order to protect the purity of the heterosexual. To the extent that the exclusion of homosexuals from public life fails, policing strategies focus on enforcing their social isolation and sequestration. Quasi-public gay spaces, well policed and removed from heterosexual public life, are permitted on the condition of their social segregation and containment. An example are gay bars that are often tolerated but only on the territorial and social margins of cities, and only on the condition that this semi-public concentration of homosexuals is unseen by the respectable heterosexual citizen. A repressive logic enforcing heteronormativity operates then by strategies of cultural pollution and censorship, criminalization and civic disenfranchisement, sequestration and violence.

Repressive strategies do not aim to eliminate the homosexual, but to preserve the division between the pure heterosexual and the polluted homosexual. Indeed, we might say that the polluted homosexual was invented in the 1950s and 1960s in order to maintain the purity of particular patterns of heterosexuality. It is not, in other words, the homosexual in general that is polluted, but a specific idea of the homosexual-for example, the homosexual as compulsively hedonistic and promiscuous. Accordingly, it is not just the homosexual that is defiled, but specific sexual-intimate practices such as pleasure driven sex or multiple partner sex. Heterosexuals who engage in such practices will experience something of the polluted status of homosexuals. Polluting homosexuality therefore purifies a particular normative heterosexual order, for example, sex that is person-and love-centered and monogamous. Hence, regimes of heternormativity not only regulate the homosexual but control heterosexual practices by creating a moral hierarchy of good and bad sexual citizens.

One unintended effect of a repressive social logic has been the development of gay social worlds. In these socially circumscribed private spaces, individuals can be recognized as homosexual. However, through at least the 1970s, these worlds survived on the margins of American society, largely hidden from the heterosexual public. To say it differently, a repressive social logic imposes on individuals the condition that we've come to call the closet-a pressure to compulsively project a public heterosexual identity by confining one's homosexuality to a private world of desire or sequestered gay enclaves. Living in the closet entails such intensive and extensive daily efforts at self-management that homosexuality often becomes the basis for a distinct social identity and way of life. This is the irony of the closet: intended to contain homosexuality the closet makes homosexuality into a primary identity and produces a desire to come out.

Thus, repressive strategies not only produce the closet but a politics aimed at gaining recognition. Gay identity politics has often been oriented to reverse a logic of homosexual repression. Thus, against the social imperative to make a secret of homosexuality, gay politics champions coming out; against the shame induced by pollution, gay pride is affirmed; against a fragmented, double life, gay politics pursues an ideal of an integrated and public gay life. Gay politics has not however challenged the construction of homosexuality as a minority identity, it has not contested the separation of sexual from gender, racial, or class politics, and it has not politicized social norms that regulate gay selves apart from the norm of heterosexuality, for 
example, norms of sexual monogamy or public sex. In short, gay identity politics has challenged a repressive politics but largely in the terms set by this regime of normative heterosexuality.

Gay identity politics has had considerable success. The achievement of a wide range of civic rights; the decline of polluting representations in many sectors of public culture; the intermingling of straights and gays in public life; and the entry of gays into the political arena indicate a blurring of the boundary between the heterosexual and the homosexual and accordingly a weakening of a repressive heteronormative logic.

I have found evidence for the changing social status of the homosexual in interviews I conducted. Targeting individuals who identify as gay, but who are not part of a public gay culture, and hence individuals I expected to be closeted, I found that most of them described lives beyond the closet.

Consider Clara, an 18-year-old black lesbian. Clara disclosed to her entire family when she was 14 . Today, she says, "I talk about everything with my mother and my sisters and one brother. They know about my lover...and just about everything about my lesbian life." Her comments on disclosing to her father, a Jamaican described as less tolerant, illustrates the extent to which Clara has normalized her homosexuality. "He had the biggest problem with it but it didn't matter to me because I just told him to be telling him. I wasn't telling him for approval." The way Clara deals with peers likewise points to normalization. As a freshman living in a college dorm, Clara had to deal quickly with issues of disclosure. She reports being invited to a fraternity party. Clara declined. "I'm not going, and they were like, 'why? I told them that I'm a lesbian."

Clara's relatively painless integration of homosexuality into her life is exceptional. It was more common for respondents to narrate a change from a double life to a life beyond the closet.
For example, Bill is a white, 40 year old, middle level state worker who grew up in a working class neighborhood in a small town. Bill was aware of his homosexual feelings as a child. These became more vivid when dating began in adolescence. Comments made by family, friends and his minister describing homosexuals in demeaning ways led bill to follow the straight pattern of his peers. By early adulthood, he had married, joined the marines, and started drinking to manage what he described as a closeted life. Perhaps triggered by the end of his marriage and his decision to get sober, Bill, now in his late-30s, decided to integrate his homosexuality into his life. He disclosed initially in the gay world and gradually to his entire family and indeed to his hometown as Bill was interviewed by a local newspaper on being gay and Christian. Today, his homosexuality is conventionalized to such a degree that his life should not be described by the concept of the closet. For example, when his son was 10 Bill tried to explain that he was gay. His son didn't respond. From time to time Bill would reintroduce this topic but his son showed little interest. Bill decided to be relaxed about it. "I would be completely myself in front of him, and that included conversations with gay friends, or talking about gay people or places...I was in a relationship and I let him see us hugging and kissing. I was just trying to show him that...it was natural for us."

Like Bill, Mike concealed his homosexuality from family and friends until he was 40. Since 1991, Mike has been deliberate in disclosing his homosexuality. "I'm very free about being gay and don't want anybody to assume that I'm not." In this regard, Mike has a picture of his partner on his desk at work. Mike does not however disclose to all his coworkers, but not for reasons of fear or shame, which would be indicative of the closet. With coworkers his decision to disclose "depends on the way the conversation runs. If someone asks me if I'm married...I say that I'm with a man." With some coworkers, Mike would not disclose because "I probably would never have an opportunity to share anything personal with them." Mike approaches his homosexuality as part of a class of "intimate" or personal information, like say religion or financial matters. Disclosure decisions 
hinge on the degree of intimacy established or desired. In short, like Clara and Bill, Mike has normalized his gay identity [for a more elaborated statement of this argument, see Seidman et al. 1999].

Social resistance to normalizing gay identities remains strong. Many Americans still feel compelled to live closeted lives. Moreover, acceptance by family, friends and coworkers does not necessarily translate into institutional integration. Key social institutions, from families to schools and the military, continue to be organized by a norm of heterosexuality that is enforced by repressive strategies. My claim though is that for many individuals today managing homosexuality may involve episodic practices of concealment but these do not create a primary gay identity or a distinctive gay way of life. This argument suggests the end of the era of the closet, but not the end of normative heterosexuality as an institution.

If heteronormativity is sustained today less by repressive strategies, how is it maintained? To address this question, I studied American films between 1960 and 1997. I found that a shift is occurring from a dominant pollution logic, which pivots around a rigid social and symbolic division between the pure heterosexual and the defiled homosexual, to a normalizing logic. The latter recognizes gay identities but only on the condition that every other key aspect of the gay self exhibits what would be considered "normal" gender, sexual, familial, work, and national practices. Ultimately, normalization is a strategy to neutralize the critical aspects of a gay movement by rendering sexual difference a superficial aspect of a self who in every other way reproduced an ideal of a national citizen.

Consider the film "Philadelphia" in many ways a breakthrough movie as it brought the issue of homosexuality and AIDS to the American mainstream. You may recall that the story is about the firing of a lawyer (Andy played by Tom Hanks) ostensibly because he has AIDS. Andy sues and wins. The film is also about the pathology not of homosexuality but of homophobia. It is the homophobia of the law firm that fires Andy and the bigotry of Joe, the lawyer who defends Andy played by Denzel Washington, that is presented as a social problem. In other words, "Philadelphia" asserts the normal status of the homosexual. From the very first scene, Andy is "out" and reveals no moral anguish over his gay identity. If there is a coming out story, its Joe's struggle to normalize Andy's gay identity.

Through the figure of Joe, the film narrates a story of a shift in the logic of normative heterosexuality from pollution/repression to normalization. Joe initially pollutes homosexuals. Consider the scene where Andy approaches Joe for legal representation. As they are shaking hands, Andy tells Joe that he's seeking representation in an AIDS suit. Joe abruptly withdraws his hand, steps back, watches everything Andy touches on his desk, and declines to take the case for personal reasons, which he subsequently discloses as his hatred of homosexuals In this scene, we can see normative heterosexuality operating as a repressive logic by establishing a hierarchical division between Joe-the normal, pure, and powerful heterosexual and Andy - the diseased, disgusting and disenfranchised homosexual.

As his relationship to Andy develops, Joe normalizes homosexuality as a minority identity. Anticipating his death, and the end of the trial, Andy has a party. At one point, Andy and Miguel are intimately embraced as they dance; Joe, who is similarly intimate with his wife, glances, then fixes on Andy and Miguel. Andy notices and smiles knowingly-as if he realizes in way that Joe doesn't quite understand yet that he is beginning to normalize Andy by viewing Andy's love for Miguel as equivalent to his love for his wife. Joe's realization comes later that evening. After the guests leave, Joe and Andy are supposed to review Andy's anticipated testimony. Instead, in a poignant scene, Andy relates to Joe the story of a Maria Callas opera that is playing in the background. It's a sad tale of injustice, love, and tragic death. As Andy is fully absorbed in the operatic narrative, Joe is fixed intently on Andy. Tears begin to well up. No words are exchanged nor do we learn Joe's thoughts. My reading is that for the first time Joe sees 
Andy as "normal" or fully human. By the end of the film, Andy has ceased to be polluted for Joe. As Andy is dying in the hospital, he signals for Joe to sit next to him. This is a dramatic moment because such physical and emotional closeness marks the end of Andy's polluted status. Joe sits on the bed and touches Andy's face as he adjusts his breathing apparatus. This act signals for Joe-and presumably the viewer-the moral equivalence of the heterosexual and the homosexual.

If this film normalizes the homosexual, it still enforces a norm of heterosexuality. For example, homosexuality is confined to individuals whose lives in every way other than their sexual orientation fall within the realm of what American culture considers to be "the normal." Thus, Andy is conventionally masculine; he's in a quasi-marital intimate relationship; he is portrayed as hardworking and economically independent; and he is a champion of the rule of law-a core part of the American creed. Indeed, the figure of Andy not only reproduces the norm of heterosexuality by normalizing a binary gender order, but Andy epitomizes dominant American family, economic, and national values. As if to reassure the viewer that normalization does not threaten normative heterosexuality, Andy's parent's heterosexuality is portrayed in ideal terms. They have been happily married for 50 years, are lovingly involved with their children and grandchildren, and are unconditionally accepting of Andy. Likewise, Joe represents an idealized heterosexual figure-he's a masculine man, married, a father, homeowner, and a successful entrepreneur. The film's message is that only the homosexual who is a mirror image of the ideal heterosexual citizen is acceptable. To the extent that legitimation is conditional on the homosexual displaying dominant social conventions, normalization demands recognition only of a minority status, not the contestation of heteronormativity.

Normalization has been bravely fought for by the mainstream of the gay movement. A life beyond the closet, which is what normalization promises, affords a kind of personal integrity that has been unattainable for many individuals. However, legitimation through normalization leaves in place the polluted status of other marginal sexualities; it sustains the dominant norms that regulate our sexual intimate conduct apart from the norm of heterosexuality.

Two political responses to normalization stand out. First, new sexual identity movements have emerged. For example, marginal sexual groups within gay life have emerged advancing their own demands for rights based on claims of victimization. Indeed, their claims to sexual citizenship have been made against both the straight and the gay mainstream. For example, a bisexual and lesbian and gay $S / M$ movement has had to struggle against the gay mainstream, which, in its quest for respectability, has echoed straight America's pollution of bisexuality and S/M. To the extent that bisexual and S/M politics aim at normalization they reproduce the identity political logic of the gay movement by claiming a distinct identity, by countering polluting with normalizing representations, and by aspiring to equal citizenship status.

A second response to normalization has been the rise of a queer politics. Whereas gay identity politics aims to change the status of homosexuality from a deviant to a normal identity, queer politics struggles against normalizing any identity. Queers are not against identity politics but aim to deflate its emancipatory narrative by exposing its exclusionary and disciplinary effects. For example, identity politics imposes a norm of sexual identification [e.g. to identify as gay, straight or bisexual] and projects a normative construction of this identity [e.g. of gays as white, young, lean bodied men]. Moreover, sexual identity politics is said to leave in place norms that sustain sexual hierarchies unrelated to gender preference, for example, a norm that privatizes sex or a norm of monogamy. Queers are not in principle against normative regulation but against normalizing social controls.

A queer perspective holds that normalizing social controls assign a moral status of normal and abnormal to virtually every sexual desire and act. This creates a global division between good and bad sexualities and normal and deviant sexual citizens. Moreover, extensive 
institutional interventions into intimate life are justified for the purposes of preventing or minimizing the undesirable public consequences of sexual pathology. In short, by investing sexuality with heightened moral and social meaning, normalizing discourses justify and bring into being a wide network of controls that regulate sexual behavior. Queer politics is then critical of any political strategy that aims only to redraw moral boundaries to include a deviant practice within "the normal"-without challenging the regulatory power of the category of the normal.

The queer critique of normalization underscores its aim to defend the social de-regulation of sex. Movements such as Queer Nation, Sex Panic! and Lavender Menace has struggled to remove large stretches of sexual intimate life from institutional control. But what moral and political ideal underpins this sexual politics?

By way of a conclusion, I want to comment on the normative grounds and political vision of a queer politics.

Queer politics assumes what I would call a "communicative" sexual ethic. In contrast to a normalizing ethic, which holds that sex acts have inherent moral significance or that sexual desires can be classified as either normal or abnormal or good or bad by virtue of their intrinsic qualities, a communicative ethic maintains that sex acts are given moral meaning by their communicative context. In other words, the qualities of a sexual desire or act per se cannot be the basis for determining its moral status. Accordingly, the focus of normative evaluation shifts from the sex act to the social exchange. Instead of determining whether a specific sex act is normal, critical judgement would focus on the moral features of a social exchange, e.g., does it involve mutual consent, are the agents acting responsibly and respectfully, is there erotic-intimate reciprocity. Thus, in assessing the legitimacy of S/M the relevant consideration would be the communicative practice of the agents, not the particular qualities of $\mathrm{S} / \mathrm{M}$ such as the use of pain or role-playing.
A communicative sexual ethic suggests that most sexual practices should be viewed as matters of personal or aesthetic not moral choice. It follows that many sexual practices would loose their moral and hence broader social significance. There would be less justification for social intervention beyond regulating behavior that involves coercion or minors. Accordingly, the range of legitimate sexual choice would expand considerably beyond what is permissible in a normalizing sexual culture. Thus, if $\mathrm{S} / \mathrm{M}$ were viewed as lacking intrinsic moral meaning, there would be no warrant for controlling this practice beyond regulating the social exchange. $S / M$ between consenting adults would become a matter of aesthetic taste not a focus of morality and not a site of social regulation.

A queer politics advocates then shifting large stretches of bodily, sexual, and intimate practice from the sphere of morality to that of aesthetics. This de-legitimates extensive state and social institutional control over intimate life. At the root of queer politics is a libertarian standpoint.

In this regard, a queer politics draws heavily on liberal notions of bodily integrity and privacy. Sexual autonomy is said to presuppose individuals who can exercise a wide range of choice over bodily based pleasures and intimacies. Accordingly, a queer concept of sexual freedom involves a robust defense of a private sphere that is juridically and socially protected from interference by the state and other citizens. However, in contrast to liberal traditions, which often anchor notions of bodily and self integrity in natural law traditions, queers deconstruct appeals to a transcendent order of nature or reason. It is this natural law grounding, with its essentialist ideas about self and sexuality that partially explains the historic alignment of liberalism with a normalizing sexual politic. For example, if sexuality is assumed by nature to be heterosexual or procreative, the range of legitimate forms of sexual identity and intimacy are greatly restricted. As sexual practices are reinterpreted as belonging to the realm of social convention, establishing moral boundaries becomes a site of contestation involving arguments that lean more on the justificatory 
language of context, consent, and consequence then that of nature and normality.

Yet, libertarianism is limited as a politic. A concept of sexual autonomy assumes individual access to social resources (expertise, financial assistance, and information). For example, a condition of sexual autonomy for women would surely include access to family planning services, including abortion. Given the economic inequality among women, sexual autonomy would have to include state aid to lower income women as a condition of exercising their reproductive rights. Similarly, if a notion of sexual autonomy presupposes that individuals have sexual knowledge to make informed choices, state enforced sex education in public schools should be part of a queer sexual politics. Hence, a queer politics would simultaneously advocate removing a wide range of sexual intimate practices from institutional regulation, and offer democratic justifications for state intervention to create the material and cultural conditions of sexual autonomy.

\section{Reference}

Seidman, Steven, Meeks, Chet, and Francie Traschen. 1999. "Beyond the Closet? The Changing Social Meaning of Homosexuality in the United States." Sexualities 2 (Feb.): 9-34.

\section{UNDERSTANDING MEN: GENDER SOCIOLOGY AND THE NEW INTERNATIONAL RESEARCH ON MASCULINITIES}

\author{
R. W. CONNELL \\ University of Sydney
}

Clark Lecture, Department of Sociology

University of Kansas, 19 September 2001

Social Thought \& Research, 2002, Vol. 24, 1\&2

\section{Introduction: debates about men and boys}

In the last decade there has been an upsurge of concern with issues about men and boys. In the public realm there have been social movements focussed on the reform or restoration of masculinity, such as the "mythopoetic" movement, the Million Man March and the Promise Keepers (Messner 1997). In education there has been much talk of boys' "failure" in school and the need for special programs for boys (Connell 1996, Gilbert and Gilbert 1998). In health there has been increasing debate about men's health and illness (Sabo and Gordon 1995, Schofield et al. 2000). A popular therapeutic movement addresses men's problems in relationships, sexuality and identity.

In a way this is surprising, because men remain the principal holders of economic and political power. Men make up a large majority of corporate executives, top professionals, and holders of public office. Worldwide, men held $93 \%$ of cabinet-level posts in 1996, and most top positions in international agencies (Gierycz 1999). Men continue to control most technology and most weaponry; with only limited 